\title{
ATUAÇÃO DE CONSÓRCIOS DE EXPORTAÇÃO BRASILEIROS NO SEGMENTO DE MODA PRAIA
}

\section{ACTIVITIES OF BRAZILIAN EXPORT JOINT VENTURES IN THE BEACH FASHION SEGMENT}

\section{BRENO DE PAULA ANDRADE CRUZ}

Mestre em Administração Pública pela Escola Brasileira de Administração Pública e de Empresas da Fundação Getulio Vargas (Ebape-FGV). Analista de Qualidade do Instituto de Desenvolvimento Educacional da Fundação Getulio Vargas (IDE-FGV) e professor da Universidade do Grande Rio Prof. José de Souza Herdy (Unigranrio). Praia do Botafogo, 190, 12a andar, Botafogo - Rio de Janeiro - RJ - CEP 22250-900 E-mail: breno.cruz@fgv.br

DEBORAH MORAES ZOUAIN

Vice-diretora e chefe do Centro de Formação Acadêmica e Pesquisa da Escola Brasileira de Administração Pública e de Empresas da Fundação Getulio Vargas (Ebape-FGV). Praia do Botafogo, 190, sala 538, Botafogo - Rio de Janeiro - RJ - CEP 22250-900 E-mail: deborah.zouain@fgv.br 


\section{RESUMO}

O artigo aborda qualitativamente a atuação de consórcios de exportação no segmento moda praia no Brasil, na perspectiva do marketing. Utilizando o método da Grounded Theory, este estudo visa identificar categorias que compõem e influenciam o desempenho exportador de três consórcios de exportação do segmento de moda praia. Este artigo se torna relevante ao elencar as categorias encontradas por meio da pesquisa de campo e apresentar as relações entre elas. Essas categorias foram caracterizadas como grandes, intermediárias e iniciais, com o propósito de identificar os seguintes aspectos: a) as características presentes apenas nos consórcios estudados, b) o composto promocional por meio destas e c) as características presentes no segmento de moda praia dos consórcios estudados. $\mathrm{O}$ artigo apresenta implicações teóricas e gerenciais ao apresentar duas grandes categorias que são relevantes na atuação de consórcios de exportação no mercado externo: conhecimento de marketing no mercado externo e características do consórcio.

\section{PALAVRAS-CHAVE}

Consórcio; Exportação; Marketing; Moda praia; Mercado.

\section{ABSTRACT}

The article takes a qualitative approach to the activities of export joint-ventures in the beachwear fashion segment in Brazil from a marketing standpoint. Using the Grounded Theory method, the study seeks to identify categories that comprise and influence the export performance of three export joint-ventures of the beachwear fashion segment. The relevance of this article lies in highlighting categories encountered by means of field research and presenting the relationships between them. These categories were identified as major categories, intermediary categories and preliminary categories, and the objective was, respectively, to: a) identify characteristics present only in the joint-ventures studied; b) identify the promo- 
tional mix through them; c) characteristics present in the beachwear fashion segment of the joint-ventures studied. The article presents theoretical and managerial implications by presenting two major categories that are relevant in activities of export joint-ventures in foreign markets, namely marketing know-how in the foreign markets and joint-venture characteristics.

\section{KEYWORDS}

Export; Joint-venture; Marketing; Beach fashion; Market.

\section{INTRODUÇÃO}

A temática das exportações no Brasil tem assumido um certo destaque na política econômica do país após a entrada de micro e pequenas empresas no mercado internacional. A participação dessas empresas no mercado externo pode acontecer de duas maneiras: individualmente ou em conjunto com outras empresas de um mesmo segmento ou região. A este último fenômeno dá-se o nome de consórcios de exportação. Entretanto, essa união não é sinônimo de sucesso no desempenho exportador, uma vez que as estratégias de marketing adotadas por cada consórcio podem definir sua atuação positiva ou negativa no mercado internacional.

Um consórcio de exportação, de acordo com Minervini (200I), é a união jurídica de micro e pequenas empresas de uma determinada região ou segmento que objetivam a inserção de seus produtos ou serviços no mercado externo. As duas classificações mais utilizadas de consórcios no Brasil são: promocional e operacional. O primeiro se caracteriza como a união das empresas para promover seus produtos ou serviços no mercado externo, porém as vendas das empresas acontecem separadamente. Já no consórcio do tipo operacional, as empresas atuam juntas em todas as etapas do processo de exportação - desde o planejamento da produção até a entrega do produto final ao importador, o que permite ao consórcio que o preço de venda não seja calculado apenas em cima dos custos de produção.

Ao comparar as estratégias de marketing adotadas por um consórcio de exportação e uma pequena exportadora do Pólo de Moda Íntima de Nova Friburgo, Cruz (2004) apresenta as principais vantagens mercadológicas de um consórcio de exportação: redução do efeito de sazonalidade do segmento, ganhos de escala com fornecedores, rateio entre as empresas de custos relativos à pesquisa de marketing no mercado internacional e participação em eventos internacionais.

Dado esse contexto do segmento de moda praia, tem-se como problema de pesquisa a seguinte questão: quais são as categorias que influenciam o desem- 
penho exportador de três consórcios de exportação do segmento de moda praia no Brasil? Dessa forma, o objetivo geral desta investigação é identificar, por meio da pesquisa de campo de caráter qualitativo, as categorias e subcategorias que influenciam o desempenho exportador dos consórcios desse segmento no Brasil. Como objetivo específico, procura-se: a) identificar as categorias principais que influenciam o desempenho exportador na perspectiva do marketing; b) identificar e descrever as subcategorias; e c) alocar as subcategorias às categorias, para que estas últimas componham o segmento aqui estudado.

Esta investigação é delimitada por questões que emergiram da pesquisa de campo que segue o método científico Grounded Theory. Assim, aspectos relacionados à legislação exportadora, tratados internacionais, barreiras aduaneiras ou variação cambial, embora importantes, não serão discutidos neste artigo pelo fato de não participarem das categorias encontradas - o que dá coerência à utilização do método.

No que diz respeito à relevância desta pesquisa para a prática dos consórcios de exportação no Brasil, três aspectos devem ser destacados aqui: empreendedorismo, arranjos produtivos locais e aspectos econômicos. Paradoxalmente, esses aspectos sustentam em muitas situações as pesquisas acadêmicas que utilizam o instrumento de estudo de caso, pois, conforme alguns estudos, o empreendedorismo e os arranjos produtivos locais são considerados elementos importantes na geração de trabalho e renda, dando dinâmica à economia regional e nacional. Já do ponto de vista teórico, este trabalho se torna relevante pelo fato de abordar a atuação de consórcios em um segmento em que o Brasil, progressivamente, vem se destacando e, principalmente, por existirem poucos trabalhos que abordam consórcios de exportação na perspectiva do marketing, o que se configura como uma lacuna de conhecimento na área.

Este primeiro item do trabalho fez uma contextualização da temática dos consórcios de exportação e apresentou o problema de pesquisa, os objetivos gerais e específicos e a relevância teórica e prática desta pesquisa. O próximo item apresenta a fundamentação teórica deste artigo, baseando-se no composto promocional. A metodologia do trabalho é apresentada no item 3, sendo seguida pelos resultados da pesquisa (item 4) que estrutura as categorias e subcategorias encontradas na pesquisa de campo. O item 5 discute os resultados à luz da teoria, e o item 6 apresenta as limitações e as sugestões para próximas investigações.

\section{FUNDAMENTAÇÃO TEÓRICA}

A fundamentação teórica desta investigação tem sua base consolidada na perspectiva do marketing e foi construída com base nas quatro categorias encon- 
tradas no método de pesquisa utilizado neste trabalho: a Grounded Theory. Essas quatro categorias estão relacionadas ao composto promocional na teoria de marketing: produto, promoção, preço e praça. Embora essas variáveis sejam exaustivamente discutidas em livros técnicos e em alguns artigos acadêmicos, elas são importantes no contexto desta pesquisa, pois contribuem no entendimento da atuação de marketing dos consórcios analisados neste artigo. Por ser uma temática pouco abordada em pesquisas acadêmicas em marketing, pouca bibliografia existe sobre a atuação de consórcios de exportação. O artigo de Cavusgil e Zou (I994) auxilia na base teórica deste estudo ao analisar produto, promoção, preço e praça na atuação de empresas exportadoras de cinco estados americanos.

No estudo realizado pelos pesquisadores, 79 empresas de 16 segmentos diferentes participaram da amostra. No total de 202 observações envolvendo os atores gerenciais que participavam ativamente do processo de exportação dessas firmas, Cavusgil e Zou (1994) constataram, por meio do método de análise fatorial, que as estratégias de marketing nas exportações das empresas dependiam de fatores relacionados aos mercados interno e externo. Ao detalharem os fatores que influenciam o desempenho exportador de marketing, os autores destacam a importância das seguintes variáveis no processo: adaptação do produto, adaptação da promoção, suporte do distribuidor externo (praça) e competitividade do preço.

É necessário fazer a distinção de alguns conceitos e delimitá-los neste trabalho. Nesse sentido, entende-se por desempenho exportador o resultado final de uma organização no processo de exportação de produtos ou serviços, podendo esse resultado ser influenciado pelas estratégias adotadas por empresas ou economias dos países importadores ou exportadores. Da mesma forma, apresenta-se a delimitação do conceito de export marketing strategy neste estudo. Assim, tem-se:

As estratégias de marketing em exportação são os meios pelos quais uma firma responde aos jogos de forças internas e externas que envolvem os objetivos do risco de um processo de exportação. Acaba por envolver todos os aspectos do marketing convencional: o estudo da distribuição (praça), o produto, a promoção e a fixação de preços.

A necessidade de focar as ações para o mercado internacional e ter orientação para mercado externo (OME) contribui para a consolidação de resultados positivos para as empresas exportadoras no comércio internacional. O conceito de OME, que é trabalhado por Cadogan et al. (1999) e abordado no contexto brasileiro por Macera e Urdan (2004), ressalta a importância de direcionar as ações das empresas exportadoras para o mercado externo. Logo, constata-se que a organização deve planejar sua entrada no mercado externo e não vê-lo apenas como a extensão do mercado interno. 
O conhecimento de marketing no mercado externo é uma variável condicionante no desempenho exportador. No caso de empresas brasileiras, Klotzle e Caires (2004) analisaram quantitativamente o desempenho exportador dessas empresas e perceberam que os exportadores consideram como variável mais importante a experiência no mercado internacional. Entretanto, essa experiência não está intrínseca ao planejamento ou pesquisa de marketing no mercado internacional.

A seguir, é discutida a importância de produto, promoção, preço e praça no desempenho exportador de organizações que atuam no mercado internacional. Apesar de serem apresentados separadamente, há uma necessidade de abordálos de forma sistêmica, conforme discutem Wind e Robertson (1983). Sempre que possível, dada a escassez de abordagem da temática, buscar-se-á fazer uma contextualização do tópico com os consórcios de exportação.

\subsection{PRODUTO}

O produto a ser comercializado no mercado internacional deve possuir algumas características que o façam, na maioria das vezes, distinto. Cavusgil e Zou (I994) destacam algumas características que um produto deve possuir - simultaneamente ou não - para obter um desempenho satisfatório no processo de exportação: I. ser único - não haver produtos similares que desempenhem uma função parecida; 2 . ser novo ou inovar acrescentando características não existentes em produtos similares ou concorrentes; 3. transmitir características de uma cultura específica; 4 . possuir nível tecnológico satisfatório, atendendo a alguns padrões técnicos dos países importadores; e 5. o mercado exportador do produto deve ser competitivo por natureza.

No segmento de moda praia, por exemplo, é difícil concorrer com a China, que é extremamente eficiente na padronização dos produtos e, conseqüentemente, no preço. Dessa forma, a estratégia utilizada por pequenas empresas exportadoras desse segmento, e por consórcios de exportação, é a customização das peças (CRUZ; ZOUAIN, 2005). Esse fenômeno de competição do setor têxtil entre Brasil e China exemplifica dois aspectos citados anteriormente por Cavusgil e Zou (1994): características específicas de uma cultura (no caso do Brasil, a customização das peças por meio da utilização de características nacionais) e mercado exportador competitivo por natureza (China, que dispõe de mão-deobra barata).

Aaby e Slater (1989) destacam que a descoberta de atributos únicos dos produtos e a tecnologia não são condições únicas para o sucesso do produto no mercado internacional, mesmo que muitas empresas, desde a década de I980, estejam acelerando a introdução de produtos pioneiros no mercado (HARRIGAN, I983). 
Num estudo quantitativo que envolveu empresas do Brasil, dos Estados Unidos, do Canadá e da Europa, Aaby e Slater (1989) constataram que o desempenho do produto tem forte dependência da seleção prévia dos mercados importadores. Assim, no processo de exportação de um produto, diversas variáveis são levadas em consideração, e não apenas características técnicas ou tecnológicas.

\subsection{PROMOÇÃO}

A promoção no processo de exportação é uma variável importante no contato com o importador. A promoção não se caracteriza apenas por aspectos relacionados à propaganda do produto ou serviço, apesar de importante. O contato físico com o importador é extremamente importante para a promoção de um produto. Conforme analisou Cruz (2004), a participação em feiras e missões internacionais - o contato físico com o cliente - contribuiu positivamente tanto para uma pequena empresa exportadora quanto para um consórcio de exportação em suas atuações no mercado externo. As duas organizações consideraram esse contato extremamente importante para o desenvolvimento de relações com os importadores.

Além disso, Cavusgil e Zou (I994) constataram quantitativamente em seus estudos que a peculiaridade do produto, a experiência da firma com o produto e a experiência dos consumidores com a marca são características que afetam positivamente o desempenho exportador de uma empresa. De acordo com os autores, essas características devem ser trabalhadas em conjunto no processo de divulgação de um produto.

No que diz respeito à divulgação dos produtos ou serviços aos clientes, as empresas exportadoras devem ter a disponibilidade de mídia (CAVUSGIL; ZOU, I994), ou seja, espaços em jornais e revistas especializadas. Isso implica questões relacionadas à propaganda ou publicidade da empresa. Aaby e Slater (I989) destacam que a ênfase em tais instrumentos é relevante para o aumento das vendas. Cruz (2004) apresenta empiricamente tais aspectos ao descrever a força da marca de um consórcio brasileiro no mercado internacional por meio da sua publicidade em um dos maiores jornais de moda do mundo.

\subsection{PRECO}

O preço de um produto ou serviço está condicionado à concorrência, ao ambiente, aos procedimentos logísticos, aos custos de produção, entre outros. A precificação de um produto no mercado internacional depende da estratégia da empresa, que pode ser de sobrevivência, por exemplo. As duas formas de precificação relevantes neste estudo baseiam-se nos seguintes aspectos: custos de pro- 
dução e distribuição, e criação de valor por meio de características diferenciais. Para tornar o preço competitivo, Aaby e Slater (I989) destacam que descontos ou formas de pagamento diferenciadas podem ser recursos para tornar o preço mais atraente. Mas essa estratégia deve ser usada somente quando o produto é padronizado e não possui outros diferenciais competitivos.

O preço do produto no mercado internacional é influenciado também por fatores internos, por exemplo, matéria-prima, mão-de-obra e localização geográfica. Cavusgil e Zou (i994) atribuíram à orientação tecnológica da indústria o único fator determinante no preço, já que o engajamento da empresa e a competitividade do mercado não foram variáveis significativas na amostra estudada. Entretanto, alguns estudos empíricos mostram que variáveis como impostos de importação, tratados comerciais ou atravessadores também influenciam o preço final do produto.

Ao analisarem a formação do preço no mercado interno e externo de empresas que compõem um consórcio de exportação no segmento de calçados em Santa Catarina, Ramos et al. (2005) constaram que não existiu diferença de precificação para os diferentes mercados, uma vez que as empresas se utilizavam do markup para definir o preço de venda nos dois mercados. Os autores justificaram tal verificação empírica pelo fato de as empresas não se encontrarem ainda num estágio inicial de marketing global. Já Cruz e Zouain (2005), ao analisarem empiricamente o processo de precificação de dois consórcios, argumentam que o tipo de consórcio - promocional ou operacional - é uma variável que também interfere no preço dos produtos.

\subsection{PRAÇA}

A escolha dos mercados em que as empresas irão atuar é extremamente importante para um desempenho satisfatório. Não é a fluência em um idioma ou a proximidade física que contribuirá para a atuação de uma organização no mercado externo. Na distribuição dos produtos, outras características devem ser consideradas. Cavusgil e Zou (I994) apresentam três características essenciais para o sucesso de distribuição de um produto: mercado exportador competitivo, orientação tecnológica da indústria e engajamento da empresa.

A decisão de atuar em determinados mercados contribui para algumas características relacionadas à venda e à assistência técnica de alguns produtos. Os autores consideram que a escolha do mercado auxilia na força de vendas, no conhecimento de marketing e no suporte promocional no mercado internacional. Manter representantes comerciais no mercado internacional é importante na distribuição dos produtos e na proximidade com o cliente final, o que implica maior confiança para estes últimos. 
De acordo com Cruz (2004), o planejamento da escolha dos mercados em que um consórcio deve atuar influencia no planejamento do produto, na elaboração das estratégias de promoção, no preço e também na participação em feiras e missões internacionais. Entretanto, conforme apresentam Ramos et al. (2005), algumas empresas que compõem um consórcio de exportação ainda não adotam estratégias diferenciadas para países ou regiões importadoras, mantendo uma postura global.

\section{METODOLOGIA}

A investigação realizada neste estudo tem caráter qualitativo e, portanto, utiliza os instrumentos que compõem a pesquisa qualitativa em administração. Foram analisados três consórcios de exportação do segmento de moda praia por meio de entrevistas em profundidade com o principal ator gerencial de cada consórcio. O método de pesquisa utilizado foi o Grounded Theory, pois não existem hipóteses preconcebidas e, ao mesmo tempo, há pouca teoria a respeito dos consórcios de exportação e suas atuações na perspectiva do marketing.

A escolha pela pesquisa qualitativa se deu pelo fato de a temática dos consórcios de exportação ainda ser relativamente pouco abordada nas investigações acadêmicas em administração e marketing. Além disso, a pesquisa qualitativa possibilita o surgimento de insights e especulações de um determinado contexto ou fenômeno, além da riqueza dos dados gerados na pesquisa de campo (VIEIRA, 2004).

A Grounded Theory é definida por Goulding (200I) como uma teoria desenvolvida que é baseada em dados sistematicamente reunidos e analisados, envolvendo o processo de pesquisa que é produto da contínua inter-relação de análise e coleta de dados. A utilização desse método neste artigo se dá pelo fato de existirem diferenças estruturais entre uma empresa e um consórcio de exportação. Logo, a teoria e as constatações empíricas existentes para uma empresa (independentemente do porte) podem não se adequar à dinâmica dos consórcios.

Nesse sentido, três consórcios de exportação do segmento de moda praia no Brasil foram analisados: A, B e C. Os dois primeiros estão localizados no Pólo de Moda Íntima de Nova Friburgo (RJ), e o último no Distrito Federal. Em documento interno fornecido aos pesquisadores pela Agência de Promoção de Exportações e Investimentos (Apex), constatou-se que dos treze consórcios reconhecidos pela instituição, cinco atuam no segmento de moda praia. Assim, no universo de cinco consórcios, foram escolhidos de forma intencional aqueles que poderiam contribuir significativamente, pelas suas atuações individuais, para as análises deste estudo. 
No que diz respeito ao desenho da pesquisa, esta tem um corte seccional com perspectiva longitudinal, pois resgata informações de outros períodos que contribuem para o entendimento do momento atual. Quanto à coleta de dados na entrevista em profundidade, o instrumento utilizado foi um roteiro de entrevista semi-estruturado, pré-testado com dois pesquisadores da área e dois atores gerenciais de um consórcio.

Esse roteiro teve como objetivo possibilitar que temas importantes que não se encontravam na pesquisa fossem relatados pelos pesquisados. Estes últimos foram escolhidos intencionalmente, obedecendo à noção de que era necessário entrevistar o membro do consórcio que estava mais inteirado da atuação da organização, não importando se ele era o presidente, o diretor de marketing ou o secretário executivo.

Nesta investigação, utilizou-se a Grounded Theory com o propósito de identificar uma teoria sobre um contexto ou fenômeno que está sendo investigado com base em dados coletados de uma realidade, sem existir a hipótese preconcebida de um fenômeno (VERGARA, 2005). Ademais, esse método não objetiva a generalização das análises construídas com base nos dados. Pela sistematização do uso da Grounded Theory proposta por Vergara (2005, p. IO2-IO3), apresentam-se a seguir os passos da pesquisa:

- Definição do problema de pesquisa: quais são as categorias que influenciam o desempenho exportador de três consórcios de exportação do segmento de moda praia no Brasil?

- Seleção (intencional) dos três consórcios a serem estudados.

- Seleção dos sujeitos para a realização das entrevistas.

- Inicialização do trabalho de campo e os registros referentes às entrevistas.

- Identificação dos conceitos emergentes (sensualidade, design, marca etc.) e agrupamento dos conceitos similares em categorias.

- Refinamento das categorias e integração dos resultados.

- Resgate do problema que deu origem à investigação.

- Validação da teoria por meio da checagem dos resultados com os entrevistados.

- Comparação da teoria gerada sobre consórcios na perspectiva do marketing com outros estudos, destacando as diferenças e as contribuições.

- Conclusão.

Esta seção apresentou os procedimentos metodológicos desta investigação. No próximo item, são apresentados os resultados agregados da pesquisa de campo dos três consórcios de exportação do segmento de moda praia no Brasil e também as categorias encontradas com a utilização da Grounded Theory. 


\section{RESULTADOS}

Este item do trabalho apresenta os resultados obtidos a partir da pesquisa de campo com os três consórcios de exportação do segmento de moda praia. De acordo com a utilização do método Grounded Theory, foram encontradas duas grandes categorias que caracterizam a atuação de um consórcio de exportação: conhecimento de marketing no mercado externo e características do consórcio. Já as categorias intermediárias estão relacionadas ao composto promocional: preço, promoção, produto e praça. As categorias iniciais são aquelas que estão presentes na atuação específica dos consórcios no segmento de moda praia. As três categorias foram obtidas por meio das entrevistas em profundidade com os atores gerenciais dos consórcios de exportação. A Figura I ilustra tais informações.

\section{FIGURA I}

CATEGORIAS E SUBCATEGORIAS

ENCONTRADAS A PARTIR DA PESQUISA DE CAMPO

\begin{tabular}{|c|c|c|}
\hline & & \\
\hline & $\begin{array}{l}\text { CATEGORIAS } \\
\text { INTERMEDIÁRIAS }\end{array}$ & CATEGORIAS INICIAIS \\
\hline & Produto & $\begin{array}{l}\text { Tecnologia } \\
\text { Sensualidade } \\
\text { Moldes do corpo da mulher } \\
\text { Mão-de-obra artesanal } \\
\text { Localização geográfica no Brasil }\end{array}$ \\
\hline GRANDES CATEGORIAS & Promoção & Sensualidade Brasileira \\
\hline \multirow{4}{*}{$\begin{array}{l}\text { Conhecimento de } \\
\text { Marketing no mercado } \\
\text { externo } \\
\text { Características do } \\
\text { Consórcio }\end{array}$} & & $\begin{array}{l}\text { Participação em Feiras e Missões } \\
\text { Catálogo de Vendas } \\
\text { Website } \\
\text { Conhecimento da cultura do país }\end{array}$ \\
\hline & & $\begin{array}{l}\text { importador } \\
\text { A marca Brasil }\end{array}$ \\
\hline & Preço & $\begin{array}{l}\text { Tecnologia } \\
\text { Tipo de Consórcio } \\
\text { Pesquisa de Marketing Internacional }\end{array}$ \\
\hline & Praça & $\begin{array}{l}\text { Feiras Internacionais } \\
\text { Conhecimento do Idioma } \\
\text { Representantes Comerciais } \\
\text { Contatos pelo website }\end{array}$ \\
\hline
\end{tabular}


Essa figura apresenta as categorias encontradas na atuação de três consórcios de exportação. Assim, percebe-se que o composto promocional (categorias intermediárias) tem cada um de seus elementos compostos por características específicas dos consórcios do segmento estudado. Ao mesmo tempo, o composto promocional recebe influências das grandes categorias - específicas desse tipo de organização e que emergiram da análise e interpretação dos dados da pesquisa.

A primeira grande categoria - conhecimento de marketing no mercado externo - emerge do contexto dos consórcios de exportação estudados a partir de três características presentes: conhecimento de características gerais do mercado importador, pesquisa de marketing coletiva e participação em eventos internacionais. Constata-se que essas características influenciam diretamente o composto promocional. Discutindo-se cada uma, tem-se:

- Conhecimento de características gerais do mercado importador: entender as características do mercado importador é importante na atuação do marketing de um consórcio de exportação. Esse conhecimento envolve o entendimento da cultura do país ou região importadora, o conhecimento da legislação e dos trâmites burocráticos e até possíveis representantes comerciais e distribuidores. Conforme os entrevistados, é necessário entender o mercado externo de forma sistêmica, buscando a profissionalização de suas ações de marketing por meio do levantamento sistemático de informações do mercado.

- Pesquisa de marketing coletiva: o levantamento das informações no mercado externo geralmente é oneroso. Por isso, uma das características dos consórcios é a consecução desse levantamento em parceria com as empresas consorciadas. A partir do momento que as empresas buscam informações de um mesmo segmento no exterior, elas acabam por direcionar suas ações para este mercado. Essa pesquisa coletiva, além de contribuir para o desempenho satisfatório do consórcio no exterior, contribui também para a atuação individual das empresas no mercado interno que ganham know-how.

- Participação em eventos internacionais: finalizando a grande categoria conhecimento de marketing no mercado externo, verifica-se que a participação em eventos internacionais é extremamente importante para que o consórcio melhore seu desempenho. A presença física contribui para que se melhorem a oferta do produto e o contato com o importador. Nas categorias iniciais este item será mais detalhado.

A segunda grande categoria, características do consórcio surgiu a partir de características específicas da atuação de um consórcio de exportação. Essas características são peculiares a esse tipo de organização de empresas e estão relacionadas ao tipo de consórcio e ao rateio dos custos entre as empresas. 
- Tipo de consórcio: essa característica aparece simultaneamente na grande categoria características do consórcio e também nas categorias iniciais, influenciando o preço no processo no composto promocional. No que diz respeito à grande categoria, percebe-se que o tipo promocional ou operacional do consórcio determina o desempenho de marketing do consórcio. Já nas categorias iniciais, a modalidade do consórcio tem grande influência no preço de venda dos produtos comercializados pelos consórcios.

Os consórcios A e C são do tipo operacional, enquanto o B é promocional. A grande diferença é que a modalidade operacional (em que as empresas vendem em conjunto) permite que os produtos sejam vendidos não com base no custo de produção, e sim com base na agregação de valor que ocorre por meio da customização das peças. Apesar de as empresas do consórcio B customizarem os produtos, a modalidade promocional não permite que trabalhem com o valor agregado às peças, uma vez que o preço de venda é o de custo de produção, sendo o mesmo valor praticado no mercado interno.

- Rateio dos custos: uma das características presentes em consórcios de exportação é o rateio dos custos entre as empresas que participam do consórcio. Essa característica é ressaltada por todos os entrevistados, pois estes consideram que uma pequena empresa arcar com custos referentes à pesquisa de marketing no mercado externo e à participação em eventos internacionais é quase inviável.

O composto promocional, como categoria intermediária, não será descrito nesta seção, uma vez que este já foi discutido na fundamentação teórica. Com base nessas informações provenientes da pesquisa de campo e, conseqüentemente, da construção das categorias intermediárias, é que se apresentam as categorias iniciais. Estas estão diretamente relacionadas ao segmento de moda praia, formando o composto promocional. Na maioria das categorias iniciais, as características da atuação dos consórcios são similares, e, quando necessário, serão apresentados os pontos divergentes entre os consórcios A, B ou C.

O fato de uma categoria inicial estar alocada em uma outra categoria não impede que ela seja alocada simultaneamente em outra. Assim, têm-se as categorias iniciais:

- Tecnologia: essa variável é relativamente importante nos produtos comercializados pelos consórcios. Entretanto, não se configura como condição sine qua non quando analisada pela ótica do trabalho artesanal. A tecnologia a que se referem os entrevistados diz respeito à qualidade do produto e à sua aceitação no mercado externo. Por exemplo, a lycra e o acabamento devem 
possuir características de um produto manufaturado de qualidade, mesmo que os bordados e o incremento das pedras semipreciosas encontrados nas peças os caracterizem como produtos artesanais.

- Sensualidade: essa característica é muito trabalhada, tanto nos produtos quanto na divulgação dos produtos em eventos internacionais, catálogos de venda e no website. De acordo com os entrevistados dos consórcios A e B, a sensualidade da mulher brasileira é bem explorada nas coleções. Já o consórcio C, por também trabalhar com o público infantil, trata com sutileza tal característica e evita supervalorizá-la, pois tem receio de que sua marca seja associada pelos seus importadores à prostituição no Brasil.

- Moldes do corpo da mulher: uma primeira característica analisada pelos consórcios B e C, após a participação em eventos internacionais, foi que os moldes dos corpos das mulheres brasileiras eram diferentes dos das européias, por exemplo. A partir da constatação dessas diferenças, B e C procuraram adaptar seus produtos aos padrões internacionais. Já o consórcio A, que tem sua história relacionada ao conhecimento técnico de um profissional que já atuava em exportações em outro segmento e, com sua experiência, percebeu a necessidade de conduzir uma pesquisa antes de entrar no mercado, não houve a necessidade de adaptação dos produtos - eles surgiram de acordo com os mercados em que o consórcio A iria atuar.

- Mão-de-obra qualificada e artesanal: a qualificação da mão-de-obra nos três casos foi conduzida pelo Serviço Nacional de Aprendizagem Industrial (Senai). Mesmo que no caso dos consórcios A e B, que se encontram no Pólo de Moda Íntima de Nova Friburgo, houvesse uma mão-de-obra preparada, o treinamento foi necessário para a entrada no mercado internacional. O artesanato realizado pelas bordadeiras nos três consórcios tem como objetivo customizar as peças, uma vez que seria impossível concorrer com produtos chineses que são eficientes em preço. A geração de renda para bordadeiras é um tema muito discutido na divulgação dos consórcios.

- Localização geográfica no Brasil: o fato de um consórcio de exportação se encontrar em um pólo específico de produção pode apresentar contribuições diversas. As principais contribuições estão relacionadas ao acesso à matéria-prima e mão-de-obra já qualificada, à tendência daquela região em produzir produtos de um mesmo setor e receber incentivos de ordem regional ou estadual, e à facilidade de empresas do mesmo setor cooperarem entre si para ganhos de escala, por exemplo. Os consórcios A e B se encontram na região que mais produz em escala no Brasil e, conseqüentemente, que mais exporta produtos do segmento de moda praia no país. Já o consórcio $\mathrm{C}$ está em uma região onde não existe um pólo produtivo do segmento de moda praia. 
- Sazonalidade: os produtos do segmento de moda praia apresentam uma grande sazonalidade. Nos três consórcios estudados, uma das maneiras de as empresas lidarem com tal característica foi a entrada no mercado internacional por meio dos consórcios. A partir do momento em que as empresas dos consórcios atuassem no mercado internacional, elas reduziriam a ociosidade produtiva, pois quando é verão no Brasil é inverno na Europa. Dessa forma, as empresas passaram a trabalhar o ano inteiro na produção das peças.

- Participação em feiras e missões: a participação em feiras e missões internacionais é extremamente importante para o contato com o cliente e para a exposição dos produtos aos possíveis importadores. As feiras internacionais são eventos de um segmento específico, enquanto as missões internacionais são ações da Apex que visam à prospecção de mercado de diversos segmentos (simultaneamente) para divulgar a marca Brasil. Os três consórcios têm um calendário rígido das principais feiras internacionais de moda. Os entrevistados consideram que o contato com o cliente por meio da exposição do produto é extremamente importante para a efetivação das vendas no mercado internacional. As feiras servem também para divulgar as coleções por meio de desfiles, entrega de catálogos de vendas e mini-CD, apresentando a coleção do ano.

- Catálogo de vendas: essa é a forma mais usual de apresentar a coleção aos importadores. Os catálogos de vendas dos consórcios são bem coloridos, com alta qualidade de resolução e têm um apelo visual que evidencia as características brasileiras. O catálogo do consórcio A é apresentado em quatro línguas e ressalta o trabalho social que eles desenvolvem junto às bordadeiras de baixa renda da região de Nova Friburgo. Já os consórcios B e C pretendem inserir em seus catálogos informações deste tipo por também trabalharem nesse aspecto social. A presidente do consórcio $C$ destaca que mais que divulgar tais informações no catálogo de vendas, é necessário efetivamente trabalhar a geração de renda para as bordadeiras e artesãs.

- Website: a forma mais dinâmica e menos onerosa de apresentar os produtos aos importadores é pelo website. Esse mecanismo serve como um catálogo eletrônico acessível de qualquer lugar do mundo e, principalmente, para o contato com os consórcios. Compradores interessados em adquirir os produtos ou em se tornar representantes podem fazer o primeiro contato pelo website. O consórcio B tem inovado e transferido os dados do website para um mini-CD que é oferecido aos potenciais compradores em feiras e missões internacionais.

- Conhecimento da cultura do país importador: conhecer as diferenças culturais dos países importadores é importante para que não se cometam erros 
culturais. Esse conhecimento pode ser obtido por meio de uma pesquisa de mercado ou pela vivência de um ou mais membros do consórcio em outros países. Por exemplo, de acordo com o consórcio C, o valor que o europeu dá à estação verão é imensamente maior que os brasileiros. Dessa forma, os europeus se planejam para o verão pelo fato de ser uma estação curta, ao contrário dos brasileiros que podem ir à praia em quase todos os meses do ano, pela extensão do litoral do país. Essa diferença cultural, por exemplo, ajuda na compreensão do valor que é dado aos produtos do segmento de moda praia pelos consumidores europeus.

- A marca Brasil: os consórcios exploram as cores da bandeira brasileira em suas marcas. A marca Brasil tem sido muito valorizada no segmento de moda praia e, conforme relata a presidente do consórcio C, há empresas nãobrasileiras que têm colocado em suas marcas a bandeira do Brasil. Isso acontece justamente por causa das características do povo brasileiro, que é tido como alegre, receptivo e caloroso.

São essas e outras características, na visão dos entrevistados, que fazem que os importadores paguem mais pelo produto que possui tais características.

- Pesquisa de marketing internacional: atuar no mercado internacional sem uma prévia pesquisa de marketing pode acarretar resultados positivos ou negativos, o que indica a incerteza no desempenho. O consórcio A surgiu da união de empresas que ainda não exportavam e que começaram a exportar após a pesquisa de marketing no mercado internacional. Já os consórcios B e $\mathrm{C}$ começaram a exportar antes de fazer uma pesquisa no mercado externo. Isso fez que os consórcios percebessem a necessidade de levantamento de informações sobre o mercado externo. Informações como molde do corpo da mulher européia, por exemplo, não foram consideradas, o que influenciou num desempenho não-satisfatório no primeiro ano.

- Conhecimento do idioma: o processo de comunicação com os importadores não ocorre apenas por meio dos catálogos de vendas ou pelo website. O contato com os importadores deve ocorrer nas feiras e nos próprios escritórios. Assim, um corpo técnico com fluência em alguns idiomas é necessário. Os três consórcios dispõem de pessoal capacitado para esse tipo de contato. Os entrevistados ressaltam que não adianta prospectar mercados quando não se tem fluência no idioma daqueles mercados.

- Representantes comerciais: ter representantes comerciais nos países importadores contribui significativamente para o aumento da participação dos consórcios nesses mercados. Os representantes podem ser pessoas físicas ou jurídicas. Quanto às pessoas físicas, geralmente são brasileiros residentes 
em outros países e que entram em contato pelo site após tomar conhecimento dos produtos dos consórcios. Já as pessoas jurídicas tomam conhecimento dos consórcios em feiras ou missões internacionais. No caso do consórcio A, a maioria dos seus representantes é de pessoas jurídicas de grande porte, o que contribui para maior inserção dos produtos em grandes lojas de departamentos nos países importadores. Os consórcios B e C ainda buscam representantes de grande porte para atingir um maior número de consumidores finais.

\section{CONSIDERAÇÕES FINAIS}

Quando foi lançado o problema de pesquisa desta investigação, procurou-se verificar qualitativamente quais eram as variáveis que poderiam influenciar na atuação de consórcios de exportação no segmento de moda praia, com o intuito de categorizá-las pela perspectiva do marketing. Nesse sentido, três categorias foram encontradas neste estudo por meio das análises empíricas: grandes, intermediárias e iniciais.

As categorias iniciais e intermediárias estão hierarquicamente subordinadas às grandes categorias, ou seja, o composto promocional no consórcio de exportação depende tanto do conhecimento de marketing do mercado externo como das características do consórcio. Logo, o composto promocional do consórcio receberá influência de aspectos relacionados ao conhecimento das características gerais do mercado importador, à participação em eventos internacionais, à pesquisa de marketing coletiva, além de características específicas do consórcio, como tipo do consórcio e rateio de custos.

Já as categorias iniciais compõem - simultaneamente ou não - cada elemento do composto promocional. Apesar de ter sido feita uma separação dos elementos do composto promocional na construção das categorias intermediárias, é importante entendê-lo de forma sinérgica, conforme já apontaram Wind e Robertson (1983). Isso é visível nessa constatação empírica quando, por exemplo, algumas categorias iniciais se encontram presentes simultaneamente em outras categorias intermediárias.

$\mathrm{Na}$ análise do produto nos consórcios de exportação do segmento de moda praia, verificou-se que as características do produto presentes na teoria foram encontradas nas verificações empíricas desta pesquisa. Os produtos, ao incorporarem a sensualidade e a mão-de-obra artesanal na customização das peças, corroboram o entendimento das características apontadas por Cavusgil e Zou (I994). A sensualidade e a mão-de-obra artesanal estão relacionadas àquilo que os autores caracterizam como a diferenciação do produto. A tecnologia dos pro- 
dutos e os moldes do corpo da mulher estão relacionados aos aspectos técnicos e tecnológicos. Já a localização geográfica no Brasil se relaciona ao que os autores classificam como mercado competitivo por natureza (Pólo de Moda Íntima de Nova Friburgo, por exemplo).

A variável promoção nos consórcios pesquisados recebe grande importância em suas atuações. Ao evidenciarem as peculiaridades das peças, a sensualidade da mulher brasileira, o artesanato e os bordados que carregam traços do folclore brasileiro, os consórcios divulgam por meio dos catálogos, website e eventos internacionais suas especificidades nos produtos, mas sem deixar de considerar os aspectos culturais dos países importadores. Cavusgil e Zou (I994), ao destacarem a familiaridade dos consumidores com a marca, contribuem para o entendimento da valorização (pelos três consórcios) das cores da bandeira do Brasil em suas marcas. No segmento de moda praia, as empresas brasileiras se destacam pela inovação e customização dos produtos. Nesse segmento, a marca Brasil está se consolidando. Existem empresas não-brasileiras que vêm utilizando a bandeira do Brasil em seus produtos.

No que diz respeito ao preço dos produtos, três variáveis são levadas em consideração: tecnologia, tipo de consórcio e pesquisa de marketing no mercado internacional. Quando se considera aquilo que os autores traçaram como componentes importantes na composição do preço no mercado internacional, verificase que a tecnologia dos consórcios está relacionada à orientação tecnológica da indústria. Já a pesquisa internacional de marketing está relacionada ao que os autores conceituam como engajamento da empresa e competitividade do mercado. Entretanto, destaca-se aquilo que não é verificado pelos autores - pelo fato de analisarem empresas - e que influencia significativamente o preço de venda de um produto no consórcio: o tipo de consórcio. O consórcio que trabalha na modalidade operacional tem a possibilidade de precificar seus produtos, mas não com base nos custos de produção e logística. Isso acontece pelo fato de os importadores não terem contato direto com as empresas que produzem. Já na modalidade promocional, os importadores têm o contato com as empresas e, de acordo com os entrevistados, os compradores não concordam em pagar além dos custos referentes à produção, por mais que haja diferenciação.

Por fim, quando se analisou a praça/distribuição, verificaram-se a importância da participação em eventos internacionais e a necessidade de representantes comerciais nos países importadores. Além disso, uma nova forma de distribuição e contato aparece no contexto dessas organizações: o website.

É fundamental definir os mercados em que os consórcios pretendem atuar. Depois disso, os consórcios têm que considerar as diferenças dos padrões técnicos entre o país importador e o país exportador, além das diferenças culturais que podem envolver desde crenças até aspectos econômicos. 


\section{LIMITAÇÕES E SUGESTÕES}

A impossibilidade de generalizar os resultados desta pesquisa não se caracteriza como uma limitação deste estudo por ele ser exploratório. Além disso, o método Grounded Theory não tem como objetivo generalizar as análises feitas com base em um objeto de estudo. Entretanto, analisando o segmento de moda praia no Brasil, não foi possível estudar todo o universo, que é composto por cinco consórcios de exportação, conforme dados internos da Apex. Apesar disso, foi a melhor aproximação desse universo.

O presente estudo apresenta implicações gerenciais e teóricas na abordagem dos consórcios de exportação. Nas implicações gerenciais, destaca-se a necessidade de um planejamento efetivo de marketing que considere não somente o composto promocional para organizações diversas. Do ponto de vista teórico, este estudo: I. não supre por completo a lacuna de conhecimento na temática dos consórcios de exportação e marketing, mas inova na utilização da Grounded Theory na identificação das categorias que influenciam as estratégias de marketing de um consórcio; 2. lança insights sobre o desempenho de um consórcio no mercado internacional na perspectiva do marketing; e 3. contribui para que a lacuna de conhecimento existente sobre esse objeto de investigação seja atenuada.

Como sugestão para pesquisas futuras, sugere-se que outros segmentos (móveis e calçados, por exemplo) sejam analisados no intuito de refutar ou confirmar as análises presentes neste artigo, ampliando a teoria desse campo de investigação por meio de estudos empíricos, ou, até mesmo, verificar se as dinâmicas de outros segmentos são parecidas. Hipóteses relacionadas ao desempenho exportador, à influência do marketing e do composto promocional no desempenho final de um consórcio, às características do consórcio e à relação com o composto promocional podem ser lançadas e testadas por pesquisadores que investiguem essa temática e que busquem trabalhar com uma amostra maior.

\section{REFERÊNCIAS}

AABY, N.; SLATER, S. F. Management influences on export performance: a review of the empirical literature I978-88. International Marketing Review, v. 6, n. 4, p. 7-26, I989.

CADOGAN, J. W.; DIAMANTOPOULOS, A.; MORTANGES, C. P. de. A measure of export market orientation: scale development and cross-cultural validation. Journal of Internacional Bussiness Studies, v. 30, n. 4, p. 689-707, I999.

CAVUSGIL, T. S.; ZOU, S. Marketing strategic-performance relationship: an investigation of the empirical link in export market ventures. Journal of Marketing, v. 58, p. I-2I, Jan. I994.

CRUZ, B. de P. A. Fatores críticos de sucesso no mercado internacional: estudo comparativo das 
estratégias de marketing em um consórcio de exportação e em uma empresa não consorciada. 2004. 83 f. Trabalho de Conclusão de Curso (Graduação) - Departamento de Administração e Economia, Universidade Federal de Lavras, Lavras, 2004.

CRUZ, B. de P. A.; ZOUAIN, D. M. Quais contribuições na área de marketing um consórcio de exportação pode levar às micro e pequenas empresas do setor confecções do Nordeste? Propostas a partir do estudo do Pólo de Moda Íntima de Nova Friburgo (RJ). In: SEMINÁRIO INTERNACIONAL DE GESTÃO DA INOVAÇÃO TECNOLÓGICA NO NORDESTE, 2., 2005, Fortaleza. Anais... Fortaleza: Federação das Indústrias do Estado do Ceará, 2005. (CD-ROM).

GOULDING, C. Grounded theory: a magical formula or a potential nightmare? The Marketing Review, v. 2, p. 2I-34, $200 \mathrm{I}$.

HARRIGAN, K. Strategic alliances: their new role in global competition. Columbia Journal of World Business, p. 67-69, Summer i983.

KLOTZLE, M. C.; CAIRES, C. O desempenho exportador de micro, pequenas e médias empresas brasileiras. In: ENCONTRO DA ANPAD, 28., 2004, Curitiba. Anais... Curitiba: Anpad, 2004. (CD-ROM).

MACERA, A. P.; URDAN, A. T. Orientação para o mercado externo: teste de um modelo no Brasil e sua aplicação a uma amostra de empresas exportadoras brasileiras. Revista de Administração Contemporânea, Rio de Janeiro, Anpad, v. 8, n. 2, abr./jun. 2004 MINERVINI, N. O exportador. São Paulo: Makron Books, 200 I.

RAMOS, P. M.; MAYA, P. C. da C.; BORNIA, A. C. Um estudo científico do componente preço e sua relação com o marketing mix de produto brasileiro de exportação: uma pesquisa multicasos nas empresas do consórcio de exportação de calçados de São João Batista/Santa Catarina. In: ENCONTRO DA ANPAD, 29., 2005, Curitiba. Anais... Brasília: Anpad, 2005. (CD-ROM).

VERGARA, S. C. Métodos de pesquisa em Administração. São Paulo: Atlas, 2005.

VIEIRA, M. M. F. Por uma boa pesquisa (qualitativa) em administração. In: VIEIRA, M. M. F.; ZOUAIN, D. M. (Org.). Pesquisa qualitativa em administração. Rio de Janeiro: Fundação Getulio Vargas, 2004.

WIND, Y.; ROBERTSON, T. S. Marketing strategy: new directions for theory and research. Journal of Marketing, v. 47, p. 12-25, 1983.

\section{TRAMITAÇ ÃO}

Recebido em 9/8/2006

Aprovado em 11/10/2007 